\title{
Teaching Content Using English as a Medium of Instruction at Universities in Vietnam: Issues and Solutions
}

\author{
Cam Ngo ${ }^{1}$, LaVelle Hendricks ${ }^{2}$, Tara Tietjen-Smith ${ }^{3} \&$ Quynh Dang ${ }^{3}$ \\ ${ }^{1}$ Research Assistant, Department of Education Leadership, Texas A\&M University-Commerce, Commerce, TX, \\ USA \\ ${ }^{2}$ Associate Professor of Counseling, Department of Psychology, Counseling, and Special Education, Texas \\ A\&M University-Commerce, Commerce, TX, USA \\ ${ }^{3}$ Department of Health and Human Performance, Texas A\&M University-Commerce, Commerce, TX, USA \\ Correspondence: LaVelle Hendricks, Associate Professor of Counseling, Department of Psychology, Counseling, \\ and Special Education, Texas A\&M University-Commerce, Commerce, TX, USA.
}

Received: December 13, 2017

doi:10.20849/aes.v3i1.304
Accepted: December 27, $2017 \quad$ Online Published: February 7, 2018

URL: https://doi.org/10.20849/aes.v3i1.304

\begin{abstract}
In the globalization era, English is becoming the official international language. This originates from the importance of English in the stages of integration, internationalization, and globalization. English is the language of computer science, economics, science, and technology. Actually, future Vietnamese scientists not only need to grasp the knowledge of their specializations in the Vietnamese language but also to be able to expand the international relationships with their foreign counterparts and take advantage of opportunities for joining scientific projects with their colleagues from developed countries, so that they can contribute to the global achievements of science. For that, they need to possess a good command of the English language. For aforementioned reasons, English should be used as the medium language for content instruction at Vietnamese universities. Using English as a Medium of Instruction (EMOI) becomes a necessity at Vietnamese universities on a large scale. In terms of majors and schools, priority can be given to such fields as industry, economics, technology, and natural sciences.
\end{abstract}

Keywords: English, instruction, Vietnam, learning, students, solutions

In Vietnam, the model of teaching content using EMOI has been undertaken through two stages: (1) teaching English for Specific Purpose (ESP) and (2) teaching content using EMOI. Indeed, this model has been applied at Vietnamese universities since the late 2000s. However, the adaptation of teaching content using EMOI comes with challenges and issues, such as English proficiency of students and instructors, students' learning methods, instructors' teaching methods, curricula, learning environment, and teaching and learning facilities. These issues cannot be resolved in a short period of time. The object of this article is to tap the knowledge gained from past research on content instruction using EMOI in different countries and use it in developing a framework for institutional action of Vietnamese universities in order to overcome the obstacles they are facing during the implementation of this new model of instruction.

According to Vietnamnet (2008), 48\% of employers in the Vietnam labor market used English to interview the potential applicants of which $91 \%$ of foreign employers having industry or representative offices in Vietnam required a good command of English for their employees. The labor market in Vietnam demands both English proficiency and professional knowledge from candidates for their recruiting plans and strategies. The Intel Product Vietnam reported that after one year of researching the senior students at five technical universities in the country, they had selected 40 from 2,000 graduated students. After an initial writing test, only 90 of 2,000 candidates were qualified with scores of $60 \%$ on a 100 -question writing test about the electronic field and English proficiency. In the final step of interviewing in English, only 40 of those 90 candidates were recruited and qualified to send to the Intel plant in Malaysia for further training. The recruiting rate of $2 \%$ is considered the lowest in the history of Intel's recruitment (Vietnamnet, 2008). The recruiting rate of the Intel Product Vietnam reflects the poor quality of teaching content using EMOI at the universities in Vietnam. 
Through the survey of Nguyen et al. (2009), in seven universities that have been applying content instruction in English, the findings indicated that teaching content using EMOI is encountering five major difficulties: (1) students' English proficiency; (2) students' learning methodologies; (3) content instructors' English proficiency; (4) teaching content in English methodologies; and (5) the teaching and learning environment. In this article, difficulties in students' English proficiency, students' learning methodologies, and the teaching and learning environment will be discussed and solutions for these issues will be sought.

Students' poor command of English is considered the biggest problem of content instruction using EMOI at Vietnamese universities. Nguyen et al. (2009) conducted a survey with 703 students in seven universities though out the country and found that $40 \%$ demonstrated skills of written English that do not suffice for writing essays, assignments, and theses. Another $60 \%$ of students demonstrated a proficiency level of oral English that was not good enough for expressing professional knowledge and concepts. Such poor command of written and oral English originates from improper teaching and learning methods of English as a Foreign Language (EFL) programs at high schools in Vietnam. Actually, teaching EFL at Vietnamese high schools is exam-focused. Under the high pressure of passing exams, both teacher and student concentrate on how to solve common exam problems. Teachers try their best to teach so students can pass exams and students try to study as hard as possible so that they will be able to pass exams. In addition, while EFL learning objectives are focused on vocabulary and comprehensive reading, English grammar and structure are tested at the end of programs. The contradiction between what students are learning and the content in which they are being tested makes EFL learning boring and ineffective. As a result, high school graduates bring exam-related English to the content instruction using EMOI at the universities where they are taught English for Specific Purpose (ESP). However, ESP must be developed on the solid fundament of social English. If students have good command of social English, they are able to learn ESP more effectively and vice versa. Therefore, solutions for poor English proficiency of the content instruction using EMOI are long-term plans. The solutions should be based on the imperative principles including (1) reinforcing EFL as a mandatory curriculum at secondary education, (2) teaching harmoniously four language skills: listening, speaking, reading, and writing, (3) applying task-based and content-based methodologies, and (4) focusing on a communicative approach.

According to Nguyen et al. (2009), in the medical school of Hue university, EFL instructors cooperated with content-teaching instructors to compile ESP textbooks for training courses of such specializations as English for Medical Students, English for Pharmaceutical Students, English for Nurses, and English for Technicians. Teaching and learning materials were concentrated on reading skills, grammar, and vocabulary. Students did not practice other language skills such as listening, speaking, and writing. When conducting the lectures, the instructors used Vietnamese language (L1) to assist students in accessing professional knowledge. In Ho Chi Minh City Polytechnic University, besides lectures in the Vietnamese language, students were given photocopies of content in English. Students were to grasp the professional content in English with the assistance of an ESP instructor. Then students were assigned homework in English for the next class discussion and presentation. During the next class, the content instructor ran the entire lecture in English.

The flexible use of mixed code of languages in content instruction has been applied in other countries in the region as well. For example, at Hong Kong universities, English and Chinese are used as a mixed code of languages in content instruction (Tang, 2006). However, the achievement was not as good as expected. According to Tang, two codes of languages used simultaneously in content instruction caused neither of those languages to be employed effectively.

In order to improve student English proficiency, the content instruction using EMOI must be divided into two stages of implementation: (1) teaching general English and ESP, and (2) teaching content in English. The first stage should be carried out during the first year of a 4-year bachelor's program. In this stage, both social English and ESP can be taught simultaneously with four language skills - listening, speaking, reading, and writing. In their research, Han and Dickey (2001) indicated that at the end of this stage, English proficiency might be tested prior to transferring to the stage of content instruction in English. The test would eliminate the students with weak command of English and guarantee that all transferred students would be able to follow lectures in English and grasp professional knowledge and concepts in English.

Students' English proficiency and academic capability are the key factors affecting the quality of teaching content using EMOI. Therefore, besides the aforementioned methods for improving the quality of teaching content using EMOI at Vietnamese universities, the admission procedures to English-medium universities should be primarily based on these two vital criteria. Applicants must be qualified not only for placement exams as for regular admission but for an English proficiency test as well. For English proficiency testing, the Test of English as a Foreign Language (TOEFL) and the International English Language Testing System (IELTS) should be 
used with the qualified scores that have been applied at the universities of English-speaking countries such as the U.S., the U.K., Canada, Australia, etc. for admission. The Test of English for International Communication (TOEIC) also should be applied for graduation. In fact, four language skills tested through TOEIC will contribute to guaranteeing a good English command of graduates when they enter the competitive labor market after graduation.

The content instruction using EMOI is a dual purpose: improving both professional knowledge and English proficiency (Tarone, 2004). Therefore, the content instruction using EMOI is not as simple as changing a language code, it also requires many other changes from learners including learning methodologies (Han \& Dickey, 2001). The teacher-centered method in which the teacher plays a primary role in class activities and students' responsibilities are to listen and make notes still dominates at many universities in Asian countries such as China, South Korea, Thailand, and Vietnam (Nunan, 2003). Content instruction using EMOI requires a different method of learning - the student-centered method in which the teacher is a facilitator and supporter, and students are active in class activities. The learners are to change themselves from (1) a passive role where the teacher is a controller into the active role for creating all kinds of communication, (2) the standard English into the English as lingua franca (a language systematically used to make conversation possible between people not sharing a mother tongue), and (3) communicating in English only within the classroom into communicating with non-native speakers from different cultures (Yoshida, 2002 as cited in Tarone, 2004).

In their research, Nguyen et al. (2009) found that students faced the challenges of adjusting themselves to a new learning environment of content instruction using EMOI since they were used to the passive way of learning at high school. Therefore, alongside with the aforementioned learning methods, universities need to set up an interdisciplinary course in which research and theory in learning, cognition, and motivation are addressed. Students need to be aware of the factors that impact learning and know how to apply various learning strategies.

Such courses as Learning Framework and Student Success have been employed at U.S. community colleges. These courses teach models of strategic learning, cognition, and motivation serving as the conceptual basis for the introduction of college-level student academic strategies. Students are also beginning to use critical and reflective thinking serving as the foundation for different thematic approaches using a variety of academic disciplines. Students enrolled in these courses are expected to (1) become reflective, autonomous learners, (2) understand the factors that affect learning and use this knowledge to improve their own, (3) set goals and align thought, behavior, and emotion to achieve their goals, (4) use behavior management techniques to achieve personal, academic, and career success, (5) collect, select, reflect, and connect artifacts of learning to outcomes, (6) develop habits of critical thinking, and (7) recognize when they need information and know how to find it, evaluate it, and use it appropriately.

Besides employing these courses, universities need to set up student supporting programs. For example, to acquire the learning skills in classrooms such as academic listening, note-taking, oral presentation, and group discussion, students must be trained. Other organization skills also should be taught such as setting up studying plans, managing and using studying time, selecting effective learning methodologies, and exercising research skills such as reading materials, collecting data, writing reports and theses, etc.

To create a learning environment in which students can find opportunities to use and practice social and academic/professional English becomes especially important for the content instruction in English. According to Nguyen et al. (2009), Vietnamese universities, where the content instruction using EMOI has been applied, lacked opportunities for students to communicate and practice social English as well as professional English. The libraries lacked professional materials and sources in English for students to seek professional references for their assignments, works, and research. To solve these issues, the first priority is that institutions need to turn their campuses into an environment in which English can be used and practiced not only between students and students or faculty members and students, but also among students, faculty members, administrators, and staff. It is called the "whole school approach" (Hong Kong, 2003, p. 7) in which all people on campus can communicate in English and cultural activities concerning English-speaking countries as well as debates, clubs, and games in English should be organized regularly. Such extra-curricular activities in English need to be organized in order to develop the listening and speaking skills in which Vietnamese students are weak. They also contribute to improving students' self-confidence in communicating in English and create chances for students to share studying experiences and learn from each other.

The libraries must be improved by increasing book-counts, materials, and magazines concerning the programs of teaching content in English as well as electronic libraries of all teaching and learning professions because studying content in English requires students to study outside the classroom, to conduct research, and to use 
information technology much more than other training programs at universities. The electronic libraries also need to set up necessary database connections for faculty members and students to use for instruction, study, and research because one of the most important supporting conditions for the content instruction using EMOI is information technologies to support teaching and learning. Classrooms should be equipped with teaching and studying modern facilities such as powerpoint projectors, overhead projectors, video, cassette, and movable desks and chairs for group activities (Nunan, 2003). Computer labs for accessing the Internet, function rooms for students' meetings, and teacher-student conference rooms are also the basic conditions for supporting students and faculty members to study and conduct research.

For a successful program of teaching content using EMOI, Vietnamese universities should access and investigate similar programs undertaken in the countries in the region such as Japan, Korea, and Hong Kong as well as in English-speaking countries such as the U.S., the U.K., Australia, and Canada for experiences and strategies in organizing and implementing those programs. One of the popular intensive English programs (IEP) applied successfully in the U.S. is the Integrated Approach. This method is used for foreign students with limited English proficiency (LEP) in which content and language instructors work together for students' success in both profession and language proficiency when participating in this program. This model concentrates on the following three methods used simultaneously by both language and content instructors: (1) the use of modern information technical facilities, (2) the use of creative thinking skills, and (3) the use of the student-centered method. According to the Integrated Approach, prior to implementing this method, the following stages should be undertaken: (a) teaching observation in which the language instructor visits and observes the content instructor's classes and vice versa, (b) cooperation in which language and content instructors work together on students' language and academic difficulties including reading materials, writing report and essay, and solving problems, (c) textbook research in which the instructors are to anticipate difficulties students might face when reading textbook and solving problems, (d) agreement of language and content topics and objectives in which the language class' topic is to respond to the theme of the content class, for example, when the content class' theme is "Environment," the language class' topic should be "Deforestation," and (e) identification of terminologies in which content and language instructors help students understand the terminologies used in the lecture. This is an example of the methods of teaching content using EMOI that English-medium universities in Vietnam can refer to and adapt to the real situations of teaching content using EMOI in the country.

In Vietnam, the international relationship and cooperation with different countries from around the world in science and technology, and the demand for English proficiency in recruitment strategies of the employers in the country are the most important motivations for implementing content instruction using EMOI in universities. However, to ensure the possibility of a successful program, many measures have to be carried out including, (1) developing curricula in the direction of combining Vietnam curricula with international ones, (2) selecting and training teaching staff as well as students in an effective way, (3) increasing the budget to facilitate the training process, (4) setting up a favorable environment for students in the process of training, and (5) building up models for using EMOI in Vietnamese universities.

In this article, the primary issues of teaching content using EMOI at Vietnamese universities are discussed. The solutions for the issues are also sought in order to assist English-medium universities in Vietnam to adapt valuable experiences from on-going EMOI programs in the countries of the world for achieving a successful EMOI program. This program brings extremely profound meanings to Vietnam higher education when internationalization and globalization in higher education are becoming more important and popular in the world.

\section{References}

Han, S., \& Dickey, R. (2001). Introducing Collaborations in Foreign Language Medium. JALT.

Hong Kong. (2003). Report on Review of Medium of Instruction for Secondary Schools. Hong Kong Education Commission, 7(2), 7.

Nguyen et al. (2009). Possibilities and Measures of Implementing Content Instruction Using Foreign Languages in Vietnamese Universities. Institute of Vietnam Science and Education-Ministry of Education and Training.

Nunan, D. (2003). The Impact of English as a Global Language on Education Policies and Practices in the Asia-Pacific Region. TESOL Quarterly, 37(4), 15. https://doi.org/10.2307/3588214

Tang, W. (2006). Linguistic Imperialism in Medium of Instruction Policies in Pre and Post 1997 Hong Kong. East Asian Studies Research. 
Tarone, E. (2005). School of Fish: English for Access to International Academic and Professional Communities. Journal of Asia TEFL, 21(5), 19.

Vietnamnet. (2008). Employment in Globalization Era. Retrieved from http://www.vietnamnet.vn

Yoshida, S. (2002). Transition from Learning English to Learning in English: Students' Perceived Adjustment Difficulties in an English-Medium University in Japan. Asian EFL Journal, 8(4), 9.

\section{Copyrights}

Copyright for this article is retained by the author(s), with first publication rights granted to the journal.

This is an open-access article distributed under the terms and conditions of the Creative Commons Attribution license (http://creativecommons.org/licenses/by/4.0/). 